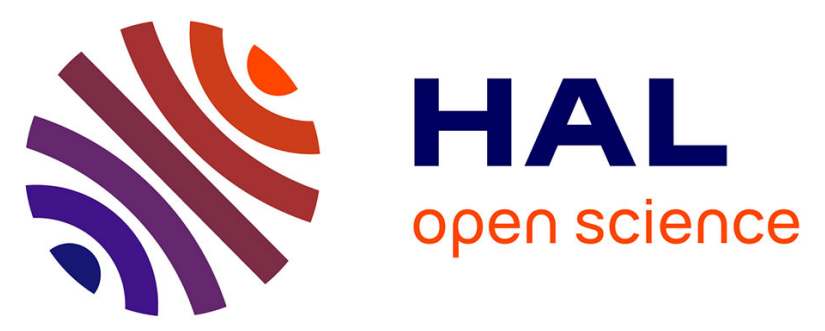

\title{
Risedronate adsorption on bioactive glass surface for applications as bone biomaterial
}

Siwar Mosbahi, Hassane Oudadesse, Bertand Lefeuvre, Allal Barroug, Hafed Elfeki, Abdelfattah Elfeki, Claire Roiland, Hassib Keskes

\section{- To cite this version:}

Siwar Mosbahi, Hassane Oudadesse, Bertand Lefeuvre, Allal Barroug, Hafed Elfeki, et al.. Risedronate adsorption on bioactive glass surface for applications as bone biomaterial. Applied Surface Science, 2016, 367, pp.205-213. 10.1016/j.apsusc.2016.01.184 . hal-01263041

\section{HAL Id: hal-01263041}

\section{https://hal-univ-rennes1.archives-ouvertes.fr/hal-01263041}

Submitted on 1 Feb 2016

HAL is a multi-disciplinary open access archive for the deposit and dissemination of scientific research documents, whether they are published or not. The documents may come from teaching and research institutions in France or abroad, or from public or private research centers.
L'archive ouverte pluridisciplinaire HAL, est destinée au dépôt et à la diffusion de documents scientifiques de niveau recherche, publiés ou non, émanant des établissements d'enseignement et de recherche français ou étrangers, des laboratoires publics ou privés. 


\title{
Risedronate adsorption on bioactive glass surface for applications
}

\section{as bone biomaterial.}

\author{
Siwar Mosbahi $^{\mathrm{a}, \mathrm{b}}$, Hassane Oudadesse ${ }^{\mathrm{a}^{*}}$, Bertand Lefeuvre ${ }^{\mathrm{a}}$, Allal Barroug ${ }^{\mathrm{e}}$, Hafed \\ Elfeki $^{\mathrm{c}}$, Abdelfattah Elfeki ${ }^{\mathrm{d}}$, Claire Roiland ${ }^{\mathrm{a}}$, Hassib Keskes
}

${ }^{a}$ University of Rennes 1,UMR CNRS 6226, Campus de Beaulieu, 35042 Rennes, France

${ }^{\mathrm{b}}$ Orthopaedic and Traumatology Laboratory Sfax Faculty of Medicine Sfax, Tunisia

${ }^{\mathrm{c}}$ Science Materials and Environement Laboratory, Sfax Faculty of Science, Sfax, Tunisia

${ }^{\mathrm{d} A n i m a l ~ E c o p h y s i o l o g y ~ L a b o r a t o r y, ~ S f a x ~ F a c u l t y ~ o f ~ S c i e n c e, ~ D e p a r t m e n t ~ o f ~ L i f e ~ S c i e n c e s, ~}$

Sfax, Tunisia

${ }^{\mathrm{e} U n i v e r s i t y ~ C a d i ~ A y y a d, ~ F a c u l t y ~ o f ~ S c i e n c e ~ S e m l a l i a ~ M a r r a k e c h ~ a n d ~ C N R S T ~ R a b a t ~ M o r o c c o ~}$

\section{Highlights:}

* The fixation of risèdronates on the bioactive glass surface has been highlighted.

* Scanning electron microscopy shows the new morphology of this composite

* Chemical analyses reveal the stability of adsorption process after $40 \mathrm{~min}$ of incubation. 


\begin{abstract}
:
The aim of the current work is to study the physicochemical interactions between bisphosphonates molecules, risedronate (RIS) and bioactive glass (46S6) after their association by adsorption phenomenon. To more understand the interaction processes of RIS with the 46S6 surface we have used complementary physicochemical techniques such as Infrared (FTIR), RAMAN and nuclear magnetic resonance (NMR) spectroscopy. The obtained results suggest that risedronate adsorption corresponds to an ion substitution reaction with silicon ions occurring at the bioactive glass surface. Thus, a pure bioactive glass was synthesized and fully characterized comparing the solids after adsorption (46S6-XRIS obtained after the interaction of $46 \mathrm{~S} 6$ and $\mathrm{X} \%$ risedronate). Therefore, based on the spectroscopic results FTIR, RMAN and MAS-NMR, it can be concluded that strong interactions have been established between RIS ions and 46S6 surface. In fact, FTIR and RAMAN spectroscopy illustrate the fixation of risedronate on the bioactive glass surface by the appearance of several bands characterizing risedrontre. The ${ }^{31} \mathrm{P}$ MAS-NMR of the composite 46S6-XRIS show the presence of two species at a chemical shift of 15 and $19 \mathrm{ppm}$ demonstrating thus the fixation of the RIS on 46S6 surface.
\end{abstract}

Keywords: Adsorption, Bisphosphonate, bioactive glass, Risedronate, Spectroscopy. 


\section{1-Introduction:}

Bisphosphonate (BP) is a germinal (structurally similar) of pyrophosphate, a natural metabolite of bone. They contain a P-R1CR2-P backbone structure (cf. pyrophosphate P-OP), which allows a great number of possible variations, either by changing the two lateral chains on the carbons (R1 and R2) or by esterification of phosphate groups. They are used to treat different bone resorbing diseases, such as osteoporosis, tumor-associated osteolysis, and hyperparathyroidism [1-3]. Today, many different compounds of the bisphosphonate family are commercially available for the treatment of bone diseases. Each bisphosphonate has its own chemical, physicochemical and biological characteristics and vary thus greatly in efficacy [1]. Furthermore, derivatives with an amino group at the end of the side chain, the length of the side chain, and nitrogen containing ring structure increase further the activity by regulating the potency of bone resorption such as risedronate (RIS).

Risedronate is a potent pyridinyl bisphosphonate currently licensed in the US for the treatment of Paget's disease of bone and it is under development for the treatment and prevention of osteoporosis. It has been shown to be effective in the treatment of Paget's bone disease $[4,5]$ and it improves or maintains bone mass for patients with postmenopausal and corticosteroid induced osteoporosis [6, 7].

The oral administration of bisphosphonate leads to several health diseases. Therefore, the regular administration of nitrogen-containing bisphosphonates causes gastrointestinal (GI) 
adverse events for some patients $[8,9]$. Indeed, the pyridinyl bisphosphonate risedronate has been shown to have a gastrointestinal safety profile similar to that of placebo $[10,11]$.

Currently, to prevent all complications of the oral administration of risedronate, experts discover other methods. Among them we mention implantlogy nevertheless these molecules can be implanted alone then it can be associated with other composites such as biomaterial. Biomaterial is a huge area, as it contains tricalcium phosphate, hydroxypatite [12, 13], calcium phosphate and bioactive glasses $[14,15]$.

Bioactive glasses are a group of surface reactive glass- ceramic biomaterials and include original bioactive glass. This group of glasses was later termed "bioactive", being "a material that elicits a specific biological response to the material surface which results in the formation of a bond between the tissues and the materials" $[16,17]$. The adhesion of bioactive glass with other molecules involves several processes such as adsorption. There are several studies have been done on the adsorption of organic molecules (therapeutic agent) on apatite surface $[18,19]$ nevertheless, nearly no study has been interested in the association of therapeutic molecule with bioactive glass by adsorption phenomenon. For this reason, the aim of this work was to combine the therapeutic agents, as risedronates, in bioactive glass to synthesize a composite to be used as a bone graft. The incorporation of risedronate into bioactive glass to form bioactive glass/risedronate composite has been achieved using the adsorption process. This paper describes the elaboration of this hybrid material and the interactions between bioactive glass and risedronate. To achieve this, we adopted a global approach using complementary physicochemical techniques such as FTIR, RAMAN and Solid MAS- NMR spectroscopy in order to learn more about the interaction processes of risedronate with bioactive glass surface.

\section{Materials and methods}




\subsection{Synthesis of bioactive glass}

Bioactive glasses were synthesized by freeze-drying method. Chemical compositions of glass were 46 mass $\% \mathrm{SiO}_{2}$ (silica), 24 mass $\% \mathrm{CaO}$ (calcium oxide or lime), 24 mass $\% \mathrm{Na}_{2} \mathrm{O}$ (Sodium oxide) and 6 mass $\% \mathrm{P}_{2} \mathrm{O}_{5}$ (Phosphorus pentoxide). The premixed mixtures were melted in platinum crucibles to avoid the risk of contamination. The fusion temperature of platinum is of $1760^{\circ} \mathrm{C}$ for that it resists to these of the $46 \mathrm{~S} 6\left(1300^{\circ} \mathrm{C}\right)$. The first rise of temperature rate was $10^{\circ} \mathrm{C} \mathrm{min}^{-1}$ and was held at $900^{\circ} \mathrm{C}$ for 1 hour until the decarbonatation of all products. The second rise of temperature rate was $20^{\circ} \mathrm{C} / \mathrm{min}$ and it was hold to $1300^{\circ} \mathrm{C}$ for 3 hours. The samples were casted in preheated brass molds, in order to form cylinders of 13 $\mathrm{mm}$ in diameter, and annealed at $565^{\circ} \mathrm{C}$ for 4 hours near the glass transition temperature. This glass was then ground using a milling machine, and sieved to obtain particles with a size distribution of $40 \mu \mathrm{m}$.

\subsection{Adsorption experiments}

Adsorption experiments were carried out at physiological temperature ( $37 \pm 1$.C), by dispersing $50 \mathrm{mg}$ of bioactive glass powder in $5 \mathrm{~mL}$ of risedronate solutions (concentration ranging from 0.8 to $2 \mathrm{mM}$ ) in a polyethylene tube. The latter were prepared by dissolving the appropriate amount of risedronate in an aqueous $1 \mathrm{mM} \mathrm{KCl}$ solution (standard solution); the $\mathrm{pH}$ of the obtained solutions was adjusted to 7.4 using hydrochloric acid and potassium hydroxide solutions. After sonication for 1-3 min, the suspensions were incubated for 20, 40, 60 and $80 \mathrm{~min}$ without stirring and centrifuged for $20 \mathrm{~min}$ at $15000 \mathrm{rpm}$. Two Blanks were used: the first contains only the risedronate prepared and incubated in the solutions corresponding to the adsorption tests but without bioglass while the second consists of the bioactive glass also prepared and incubated in the solution. After centrifugation, the obtained 
solids were washed with deionised water and lyophilised. The supernatants were filtrated on millipore filters $(0.2 \mu \mathrm{m})$. Thus we obtained three hybrid materials: 46S6-8RIS, 46S6- 12 RIS and 46S6- 20RIS.

\subsection{Solid phase characterization}

Several physicochemical methods were employed for the characterization of the prepared bioactive glass/ risedronate composite. Phase analysis was examined by X-ray diffraction (XRD) using a BRUKER AXS D8 ADVANCE diffractometer $\left(\lambda=1.54059 \mathrm{~A}^{\circ}\right.$, BraggBrentano geometry, $2 \Theta$ range of $10-70 \circ$ for 20 min with a step size of 0.02 ). Infrared (FTIR) analyses were performed on $\sim 1 \mathrm{mg}$ of materials with metallic blade. Spectra were obtained between 4000 and $400 \mathrm{~cm}^{-1}$ wavenumber, with a resolution of $2 \mathrm{~cm}^{-1}$. Raman spectra of the samples were generated on a Horiba, Jobin-Yvon Labram HR800 confocal microspectrometer, equipped with a helium-neon LASER $(\lambda=632.82 \mathrm{~nm})$. The spectral resolution was $2 \mathrm{~cm}^{-1}$, the laser power was $2 \mathrm{~mW}$ and integration times varied from 30 to 120 s. All spectra were recorded over a wavelength range of $200-1800 \mathrm{~cm}^{-1}$. Three spectral accumulations were averaged. Nuclear Magnetic Resonance (MASS) using Bruker MAS spectrometer ASX300 (7.05 T) was employed to highlight the microstructure of all compounds and finally Scanning Electron Microscopy (SEM) using Jeol JSM 6301F was used for the morphology investigations.

\subsection{Solution analysis}

The silicon content of the solutions obtained after adsorption experiment was measured by inductively coupled plasma-Optical Emission Spectrometry (ICP-OES) method. The risedronate concentration in the filtrates was determined using UV spectrophotometric absorption at $262 \mathrm{~nm}$ (Hewlett Packard 8452A Diode Array Spectrophotometer). This 
wavelength corresponds to the maximum absorbance of the pyridine group. The calibration curve ranged from 0 to $0.43 \mathrm{mM}$. The molar absorption coefficient was approximately $3.9 \times 10^{3}$ at $\mathrm{pH} 7.4$ [20].

The concentration of risedronates $\mathrm{C}_{\mathrm{g}}(\mathrm{mM})$ in each point was calculated from the mathematical relation:

$\mathrm{Cg}=\frac{A}{(\varepsilon \times l)}$

Were:

A: Absorbance,

$\varepsilon$ : Molar extinction coefficient $\left(\mathrm{cm}^{2} / \mathrm{mol}\right)$,

1: Distance traveled by the light beam in the sample $(\mathrm{cm})$,

The relaxation time $T$ of the system has been calcumated by the using the following mathematical relation:

$$
\tau=\frac{t}{\operatorname{Ln}\left(\frac{C 0}{C 0-C g}\right)}
$$

Were:

$T$ : relaxation time of the system

$\mathrm{C}_{\mathrm{g}}$ is the risedronate concentration in each point,

$\mathrm{C}_{0}$ is the risedronate limit concentration,

$\mathrm{t}$ the incubation time

The relaxation time of the system has been calculated for RIS alone, 46S6-8RIS, 46S6-12RIS and 46S6-20 RIS after 0, 20, 40, 60 and 80 min of incubation in the $\mathrm{KCl}$ solution.

\section{Results and discussion}




\subsection{Solid phase characterization}

\subsubsection{Crystalline structures: X-Ray diffraction (XRD)}

In this current study we associated the pure bioactive glass and the $8 \%, 12 \%$ and $20 \%$ risedronate. Therefore, the XRD diagram of $46 \mathrm{~S} 6$ corresponds to an amorphous system. The diffraction halo is present between 20 and 40 ( 2 theta) with a center of $32^{\circ}$. This halo is characteristic of diffusion phenomena in the amorphous material and the absence of long range order in the matrix of biocative glass [21] whereas risedronate crystallizes in a monoclinic system, presenting several lines [22] (Figure 1)

Different compositions based on different amount of risedronateds 46S6-XRIS (8, 12 and $20 \%$ ) have been studied. Therefore, after $80 \mathrm{~min}$ of their incubation revealed an amorphous structure. There was no additional crystalline solid phase observed after risedornate adsorption in the composite 46S6-XRIS (Figure 2). The same result was revealed after the association of tiludronate with nanocrystalline apatite [23]

This was due to the association method (adsorption) which is a surface phenomenon. Moreover adsorption is the adhesion of atoms, ions, or molecules from a dissolved solid to a surface. It is a surface-based process [24]

\subsubsection{FTIR spectroscopy}

Infrared spectra of the bioactive glass (46S6), risedronate (RIS) and of composites 46S6XRIS are presented in Figures 3 and 4. For bioactive glass, the spectrum shows the characteristic bands of silica network. It reveals four broad absorption bands. First band about $503 \mathrm{~cm}^{-1}$ is characteristic to angular deformation vibration of $\mathrm{Si}-\mathrm{O}-\mathrm{Si}$ band between $\mathrm{SiO}_{4}$ tetrahedrons in silicate network. Three other characteristic bands at 745, 932 and $1036 \mathrm{~cm}^{-1}$ attributed to stretching vibrations of $\mathrm{Si}-\mathrm{O}$ band in each $\mathrm{SiO}_{4}$ tetrahedron are detected. In 
addition, only slight band at $590 \mathrm{~cm}^{-1}$ is characteristic for bending vibration of O-P-O group. It highlights the presence of a small amount of phosphate linked to the silica network [25-27]. The infrared spectrum of risedronate illustrates the presence of several bands, therefore we note the presence of $\mathrm{C}=\mathrm{O}$ bands at $1700 \mathrm{~cm}^{-1}$ and $1130 \mathrm{~cm}^{-1}$. Also we remark the presence of $\mathrm{C}=\mathrm{N}, \mathrm{C}=\mathrm{C}$ and $\mathrm{C}-\mathrm{N}=\mathrm{O}$ bands respectively at $1200 \mathrm{~cm}^{-1}$ (amide), $1666 \mathrm{~cm}^{-1}$ and 1570 $\mathrm{cm}^{-1}$. Finally, we observe the presence of P-O band at 537 and $468 \mathrm{~cm}^{-1}$ [22]. The risedronate sodium salt showed two intense bands in the $1025-1055 \mathrm{~cm}^{-1}$ region assigned to $\mathrm{C}-\mathrm{H}$ pyridine ring deformation, strongly impacted by hydrogen bonding between the pyridine ring and an adjacent phosphate group [28].

Infrared spectra of all composites 46S6-20RIS after $20 \mathrm{~min}, 40 \mathrm{~min}, 60 \mathrm{~min}$ and $80 \mathrm{~min}$ illustrate the presence of bands characterizing 46S6 and RIS. Thus, these composites reveal the presence of Si-O band at $503 \mathrm{~cm}^{-1}$ which was slightly shifted and decreased of intensity. Also we note the existence of two bands of $\mathrm{C}=\mathrm{O}$, the first at $1700 \mathrm{~cm}^{-1}$ which was slightly shifted to the right and the second at $1130 \mathrm{~cm}^{-1}$ this was with a slight intensity. We remark also the presence of $\mathrm{C}=\mathrm{N}, \mathrm{C}=\mathrm{C}$ and of $\mathrm{C}-\mathrm{N}=\mathrm{O}$ bands respectively at $1200 \mathrm{~cm}^{-1}$ (amide), $1666 \mathrm{~cm}^{-1}$ and $1570 \mathrm{~cm}^{-1}$. These were slightly shifted to the right. Finally, we notice the presence of $\mathrm{P}-\mathrm{O}$ bands at 468 and $537 \mathrm{~cm}^{-1}$. This highlights the fixation of risedonate at the surface of bioactive glass and explains the chemical reactivity of our adsorbent. This result exhibits the good chemical reactivity of bioactive glass surface. It is in good agreement with others works $[29,21]$

\subsubsection{RAMAN spectroscopy}

Raman spectra of the samples which contained bioactive glass has the characteristic broad bands at approximately 605 and $947 \mathrm{~cm}^{-1}$ corresponding to Si- O- Si rocking vibration, nonbridging Si- O and Si- O- Si asymmetric stretching modes, respectively [30]. 
Raman spectra of the combination between $8 \%$ RIS illustrates only Si-O characterizing bioactive glass. This result was explained by the low quantities of risedronate which have been associated with our bioactive glass. However, the Raman spectra of the association between bioactive glass and $20 \%$ of risedronate shows the presence of 4 bands characteristic of C-C at 249, 286, 401 and $418 \mathrm{~cm}^{-1}$. It corresponds to an association and chemical interaction between bioactive glass and risedronate. This result is in good agreement with other data reported by Barroug [22] during the association between nanocrystalline apatites and risedronate. Also this finding illustrates the interaction between bioactive glass and bisphosphonates, thus this result coincide with other studies [31]. Then, we remark the presence of C-P bands at 612 and $814 \mathrm{~cm}^{-1}$ and also the appearance of two bands of P-OH at 849 and $872 \mathrm{~cm}^{-1}$. At the same time we observe the presence of the three bands of bioactive glass at the raman shifts respectively 347, 624 and $942 \mathrm{~cm}^{-1}$. These details clarify the association of risedronate with bioglass (Figure 5).

\subsubsection{NMR spectroscopy}

The ${ }^{31} \mathrm{P}$ MAS-NMR spectrum obtained for the pure bioactive glass and the results of its decomposition, illustrates a chemical displacement which characterizes phosphorus in an orthophosphate environment $\mathrm{PO}_{4}{ }^{3-}$. It corresponds to the $\mathrm{Q}^{0}$ species.

The chemical displacement obtained for the pure bioactive glass is comprised between the chemical displacement of ${ }^{31} \mathrm{P}$ of the $\mathrm{Na}_{3} \mathrm{PO}_{4}(10$ and $16 \mathrm{ppm})$ and the ${ }^{31} \mathrm{P}$ of $\mathrm{Ca}_{3}\left(\mathrm{PO}_{4}\right)(0$ and 3ppm), which clearly illustrates the absence of binding with these compounds [39].

The ${ }^{31} \mathrm{P}$ MAS - NMR spectrum obtained for the 46S6-8RIS and the results of its decomposition shows the presence of the compound $\mathrm{Q}^{0}$ with a proportion of $100 \%$ and with a chemical shift to 8 ppm whereas the ${ }^{31} \mathrm{P}$ MAS- NMR spectrum obtained for the 46S6-12RIS and the results of its decomposition revealed the decreasing of $\mathrm{Q}^{0}$ to $93 \%$ and the appearance 
of other compound $\mathrm{Q}^{\mathrm{RIS1}}$ (compound present in the ${ }^{31} \mathrm{P}$ MAS-NMR spectra of risedronates) at a chemical displacement to $19 \mathrm{ppm}$ and with a proportion of $7 \%$. This result is in agreement with the other studies [32]

The ${ }^{31} \mathrm{P}$ MAS- NMR spectrum obtained for the 46S6-20RIS and the results of its decomposition show the presence of the compound $\mathrm{Q}^{0}$ with a proportion of $88 \%$, the increasing of the compound $\mathrm{Q}^{\mathrm{RIS} 1}$ to $8 \%$ with a chemical shift at $19 \mathrm{ppm}$, we note also the appearance of other species $\mathrm{Q}^{\mathrm{RIS} 2}$ (compound also present in the ${ }^{31} \mathrm{P}$ MAS-NMR spectra of risedronates) with a chemical displacement to $15 \mathrm{ppm}$ and with a proportion of $4 \%$. These data illustrate the fixation of risedronate to bioactive glass which revealed by the appearance of compounds characterizing risedonate in the spectratum of 46S6-12RIS and 46S6-20RIS (Figure 6 and Table 1).

The same result is reported by RAMAN spectroscopy. Then, after the association of $8 \%$ risedronates with bioactive glass, there are no additional band to 46S6 Raman spectratum and no new compound in ${ }^{31} \mathrm{P}$ MAS-NMR are revealed whereas after the association of $12 \%$ and $20 \%$ risedronate we note the appearance of new bands characterizing risedronate in the RAMAN spectratum and the appearance of new compounds in ${ }^{31} \mathrm{P}$ MAS-NMR corresponding to risedronates species. These findings could be explained by the few quantity of risedronate added to 46S6 material in the composite 46S6-8 RIS.

Findings reported by 46S6-12 RIS and 46S6-20 RIS are in conformity with the results reported by Barroug [22], after the association of risedronate to the nanocrystalline apatites and which proved by the appearance of risedronate compounds in the spectratum of the composite risedronate -naocrystalline apatites.

\subsubsection{Morphological study by scanning electron microscopy (SEM) coupled with energy-dispersive X-ray:}


The obtained results are shown in Figure 7A, 7B and 7C. The surface of 46S6 displays smooth fragments while the composite 46S6- XRIS exhibit rough surface. The risedronate crystals on the surfaces of composite are well observed. They adhered to the bioactive glass particles and created some interstices on the surface of the 46S6-XRIS composite. The risedronate molecules modify strongly the surface morphology of pure bioactive glass. They are found almost everywhere on the surface of the 46S6-XRIS composite due to their chemical affinity for calcium ions in the matrix of bioactive glass. Therefore, the combination of $8 \%$ and $12 \%$ of RIS with 46 S6 shows the presence of the filaments coming encompass the bioactive glass blocks whereas after the association of $20 \%$ RIS with 46 S6, the bioactive glass blocs is nearly encompassed by risedronate filaments. The same result is seemed after the association of risedronate with the nanocrystalline- apatite [22] and after the association of zoledronate with bioactive glass [33]. Thus, all these input illustrate the reactivity and the good chemical binding and interaction with other molecules of pure bioactive glass.

Result reported by energy-dispersive X-ray showed the decreasing of Si quantities in the 46S6-XRIS surface with the increasing of risèdronates associated with 46S6. Thus, this result highlights the SEM data. Therefore, the Si quantity decreased from 6.6 in 46S6-8RIS to 1.8 in 46S6-20RIS. This results illustrates that 46S6-20RIS surface is nearly covered by risèdronates (Figure 8: A,B, C).

\subsection{Analysis of the solutions after uptake of risedronates (solution obtained after the}

\section{filtration)}

Analyses of the obtained solutions after uptake of rideronate divulged that the binding of risedronate ions to the bioactive glass surface affected the amount of silicon ion in the solution. The evolution of this ion in solution as a function of risedronate adsorbed onto 46S6 surface in Figure 9. The release of silicon ion increased upon uptake of risedronate. The 
content of silicon ions in solution for the 46S6-20 RIS was significantly higher due to the specific solubility behavior of this type of biomaterial and the high quantity of risedronates which fixed in the silicon sites. These observations suggest that risedronate molecules substituted for silicon ions on the 46S6 surface. Several studies illustrate that the fixation of BP is accompanied by the release of some elements from the adsorbent surface such as the liberation of silicon and phosphorus. As reported by several authors [34, 35] for other BP, it can be postulated that risedronate species participate in an ionic exchange process with active mineral ions on the surfaces of bioactive glass, particularly silicon, which share the same ionic sites at the surface. Silicon intervenes in several physicochemical properties after its immersion in the SBF solution or after its in vivo experiment. Consequently, the rate of bone formation at a bioactive glass implant interface can be altered by changing the glass composition [36, 37]. However, the release of phosphorus decreased with time incubation, this attenuation is explained by the reduction of risedronate phosphorus in the solution. Thus, this explained by the decreasing of phosphorus in the solution in favor of the increasing of risedronates fixation in the 46S6 surface (Figure 10)

The binding of risedronate with bioactive glass was evaluated by using UV spectrophotometric absorption at a $\mathrm{pH}=7.4$, temperature $=25$ and at a wavenumber $\lambda=362$ nm. This wave number is chieved from the calibration of the solution with $2 \mathrm{mM}$ of risedronate (Figure 11).

The kinetic release of risedronates in $\mathrm{KCl}$ during the association of risedronate with bioactive glass was studied by UV visible. Therefore, we note that the release of this molecule reaches its threshold for compounds 46S6-8RIS, 46S6-12RIS and 46S6-20RIS after $40 \mathrm{~min}$ of incubation. This result illustrates the maximum attachment of risedronates on 46S6 after 40 min and exhibits the fixation of RIS on the 46S6 surface with a speedy kinetic (Figure 12). Others similar results were reported by the literature of the interaction of apatite with different 
bisphosphonates [38], with the adenosine 5- monophosphate [39] and with phosphocitrates [40]. This finding explains the high reactivity of the 46S6 surface to the molecules of biological interest. Additionally, this result explains that resedronate presents an early release due to its hydrophilic character, the same results is reported in previous works after the immersion of gentamicin sulfate in the PBS solution [41].

T min of 46S6- 8RIS, 46S6-12RIS and 46S6-20 RIS system relaxation respectively after 0 min, $20 \mathrm{~min}$, $40 \mathrm{~min}, 60 \mathrm{~min}$ and $80 \mathrm{~min}$ for each composite increased between $20 \mathrm{~min}$ and 40 min then they were stabilized. This data discloses that risedronates achieve its threshold of release after 40 min (Figure 13).

The comparison of $\Delta$ (T min) of all composites 46S6-8RIS, 46S6-12 RIS and 46S6-20 RIS reveals its increasing with the rise of risedronates quantity added to 46S6.

\section{4-Conclusion:}

This study suggests that risedronate adsorption on bioglass supports corresponds to an ion substitution reaction with silicon ions at the crystal surface. This mechanism explains the reactivity of 46S6 surface. Moreover, the association between 46S6 and risedronate is showed by the appearance of bands characterizing 46S6 and risedronate in the composites 46S6-8RIS, 46S6- 12RIS and 46S6-20RIS after its characterization by FTIR and RAMAN spectroscopy. This association is confirmed also by MAS-NMR ${ }^{31} \mathrm{P}$ therefore we show the presence of species characterizing RIS in the composites BG-12RIS and BG-20RIS. Bioactive glass/ risedronate association was demonstrated also by using of SEM micrograph and XRD diffraction but most clearly with Raman, FTIR and MAS-NMR. Chemical analyses illustrate that the fixation and the release of risedronates achieved its maximum after $40 \mathrm{~min}$ of incubation. The combination of FTIR, Raman, solid NMR spectroscopy and chemical 
analyses proved to be a powerful multidisciplinary approach to understand the interaction between bioglass and bisphosphonate molecules.

\section{Acknowledgement}

The authors would like to acknowledge Francis GOUTTEFANGEAS and Loic JOANNY (CMEBA, University ' of Rennes 1), for their help and their contribution during this work. Authors also would like to acknowledge CNRST at Rabat Morocco for the FINCOME program and Minister of education and research, Tunisia. 


\section{References:}

[1] H. Fleisch, Bisphosphonates: Mechanisms of action, Endocr. Rev. 19 (1998) 80-100.

[2] H.A. Fleisch, Bisphosphonates Preclinical aspects and use in osteoporosis, Ann. Med. 29 (1997) 55-62.

[3] R. E. Coleman, Metastatic bone disease: Clinical features, pathophysiology and treatment strategies, Cancer. Treat. Rev. 27 (2001) 165-76.

[4] O. Reigstad, C. Johansson, V. Stenport, A. Wennerberg, A. Reigstad, M .Røkkum, Different patterns of bone fixation with hydroxyapatite and resorbable $\mathrm{Ca} \mathrm{P}$ coatings in the rabbit tibia at 6, 12, and 52 weeks, J. Biomed. Mater. Res B. Appl. Biomater. 19 (2011) 14-20 [5] M. Jarcho, Calcium phosphate ceramics as hard tissue prosthetics, Clin. Orthop. Relat. Res. 157 (1981) 259-78.

[6] X.H. Xie, X.W. Yu, S.X. Zeng, R.L. Du, YH Hu, Z .Yuan, E.Y .Lu , K.R. Dai , T.T. Tang , Enhanced osteointegration of orthopaedic implant gradient coating composed of bioactive glass and nanohydroxyapatite, J.Mater. Sci. Mater .Med. 21 (2010) 2165-73.

[7] L.L. Hench, Bioactive ceramics: Theory andclinical application, In. bioceramics. 7 (1994) $3-14$.

[8] P.C. de Groen, D.F. Lubbe, L.J. Hirsch, A. Daifotis, W. Stephenson, D. Freedholm, S. Pryor-Tillotson, M.J. Seleznick, H. Pinkas, K.K .Wang, Esophagitis associated with the use of alendronate, N. Engl. J. Med. 335 (1996) 1016-1021. 
[9] B. Ettinger, A. Pressman, J. Schein, Clinic visits and hospital admissions for care of acidrelated upper gastrointestinal disorders in women using alendronate for osteoporosis, Am. J. Manag. Care. 4 (1998)1377-1382.

[10] S.T. Harris , N.B. Watts , H.K. Genant, C.D. McKeever, T. Hangartner, M. Keller, CH III. Chesnut , J. Brown, E.F. Eriksen, M.S. Hoseyni , D.W. Axelrod, P.D. Miller, Effects of risedronate treatment on vertebral and nonvertebral fractures in women with postmenopausal osteoporosis: a randomized controlled trial. Vertebral Efficacy With Risedronate Therapy (VERT) Study Group, JAMA. 282 (1999)1344-52.

[11] S. Cohen, R.M. Levy, M. Keller, E. Boling, R.D. Emkey, M. Greenward, T.M. Zizic, S. Wallach, K.L. Sewell, B.P. Lukert, D.W. Axelrod, A.A. Chines, Risedronate therapy prevents corticosteroid-induced bone loss, Arthritis Rheum. 42 (1999) 2309-2318.

[12] H. Oudadesse, E. Dietrich, X.V. Bui, Y. Le Gal, P. Pellen, G. Cathelineau, Enhancement of cells proliferation and control of bioactivity of strontium doped glass, Appl. Surf. Sci. 257 (2011) 8587-8593.

[13] A. M. Mostafa, H. Oudadesse, A. Mahmoud, M. El-Gohary, Fabrication, characterization and drug release of ciprofloxacine loaded porous polyvinyl alcohol/bioactive glass scaffold for controlled drug delivery, Bioceram Dev Appl. 4 (2013) 1-4

[14] S. Mosbahi, H. Oudadesse, H. Elfeki, M. Trigui, E. Wers, T. Rebai, A. Elfeki, H. Keskes, Zinc-doped bioactive glass in filling of loss bone of diaphyseal bone substance in NZW rabbits, IJET. 3 (2014) 2277-3754,

[15] S. Jebahi, H. Oudadesse, M. Saoudi, F. Kallabi, P. Pellen, T. Rebai, A. Elfeki, H.Keskes, Cytocompatibility, gene-expression profiling, apoptotic, mechanical and 29Si, 31P solid state nuclear magnetic resonance studies following treatment with a bioglass-chitosan composite , Biotechnol Lett. 36 (2014) 2571-2579

[16] L.L .Hench, R . J. Splinter, W.C. Allen, T.K. Greenlee, Bonding mechanisms at the 
interface of ceramic prosthetic materials, J. Biomed. Mater. Res. 5 (1971) 117-141.

[17] C.S. Hsi, H.Z. Cheng, H.J. Hsu, Y.S. Chen, M.C. Wang, Crystallization kinetics and magnetic properties of iron oxide contained 25Li2O-8MnO2-20CaO-2P2O5-45SiO2 glasses, J. Eur. Ceram. Soc. 27 (2007) 3171-3176.

[18] S. Ouizat, A. Barroug, A. Legrouri, C. Rey, Interaction between a bisphosphonate, tiludronate and nanocrystalline apatite: in vitro viability and proliferation of HOP and HBMSC cells, Mater. Res. Bull. 34 (2000) 2279-2289.

[19] L. Benaziz, A. Barroug, A. Legrouri, C. Rey, A. Lebugle, Adsorption of Phospho Serine and Serine onto Poorly Crystalline Apatite, J. Colloid. Interface. Sci. 238 (2001) 48-53.

[20] P.T. Vallano, S.B. Shugarts, W.F. Kline, E.J. Woolf, B.K. J. Matuszewski, B, Determination of risedronate in human urine by column-switching ion-pair high-performance liquid chromatography with ultraviolet detection, Chromatogr. 794 (2003) 23-33

[21] H. Oudadesse, E. Dietrich, X.Y. Bui, Y. Le Gal, P. Pellen, G. Cathelineau, Enhancement of cells proliferation and G1 of bioactivity of strontium doped glass, Appl. Surf. Sci. 257 (2011) 8587-8593.

[22] F. Errassi, S. Sarda, A. Barroug, A. Legrouri, H. Shi, C. Rey, Infrared, Raman and NMR investigations of risedronate adsorption on nanocrystalline apatites, J. Colloid Interface. Sci. 420 (2014) 101-111.

[23] P. Pascaud, R. Bareille, C. Bourget, J. Amedee, C. Rey, S. Sarda, Interaction between a bisphosphonate, tiludronate and nanocrystalline apatite: in vitro viability and proliferation of HOP and HBMSC cells, Biomed. Mater. 7 (2012) 1-9.

[24] A. Barroug, E. Lernoux, J. Lemaitre Paul, G. Rouxhet, Adsorption of Catalase on Hydroxyapatite, J. Colloid Interface. Sci. 208 (1998)147-152

[25] M. Sitarz, W. Mozgawa, M. Handke, Rings in the structure of silicate glasses, J. Mol. Struct. 511 (1999) 282-285. 
[26] M. Handke, M. Sitarz, M. Rokita, E. Galuskin, Vibrationnal spectra of phosphatesilicate biomaterials, J. Mol. Struct. 651 (2003) 39-54.

[27] S. A. MacDonald, C. R. Schardt, D. J. Masiello, J. H. Simmons, Dispersion analysis of FTIR reflection measurements in silicate glasses, J. Non-Cryst. Solids. 275 (2000) 275-282.

[28] N. Redman-Furey, M. Dicks, A. Bigalow-Kern, R.T. Cambron, G. Lubey, C. Lester, D. Vaughn, Structural and analytical characterization of three hydrates and an anhydrate form of risèdronates, J. Pharm. Sci. 94 (2005) 893-911.

[29] E. Dietrich, H. Oudadesse, A. L. Girot, M. Mami, In vitro bioactivity of melt- derived glass 46S6 doped with magnesium, J. Biomed. Mater. 10 (2007) 1002-31901.

[30] P. Gonzalez, J. Serra, S. Liste, S. Chiussi, B. Leon, M. Perez-Amor, Raman spectroscopic study of bioactive silica based glasses, J. Non-Cryst. Solids. 320 (2003) 92-99. [31] K. Rosenqvista, S. Airaksinena, S. J. Fraserb , K . C. Gordonb, A. M. Juppo, Interaction of bioactive glass with clodronate, Int. J. Pharm. 452 (2013) 102- 107.

[32] J. Kos , M. Pentakova, Z. Oktabec, L. Krejcik, Z. Mandelova ,P. Harokova, J. Hruskova, T. Pekarek, O. Dammer, M. Tkadlecov, J. Havlicek, J. Vinsova, V. Kral, J. Dohnal, J. Jampílek, Crystallization Products of Risedronate with Carbohydrates and Their Substituted Derivatives, Molecules. 16 (2011) 3740-3760.

[33]. X.V. Bui, H. Oudadesse, Y. Le Gal, A. Mostafa, P.Pellen, G. Cathelineau, Chemical Reactivity of Biocomposite Glass-Zoledronate, J .AUST. CERAM. SOC. 46 (2010) 24-28.

[34] A. Juillard, G. Falgayrac, B. Cortet, M.-H. Vieillard, N. Azaroual, J.-C. Hornez, G. Penel, Molecular interactions between zoledronic acid and bone: an in vitro Raman microspectroscopic study, Bone. 47(2010) 895-904. 
[35] S. Josse, C. Faucheux, A. Soueidan, G. Grimandi, D. Massiot, B. Alonso, P. Janvier, S. Laib, P. Pilet, O. Gauthier, G. Daculsi, J. Guicheux, B. Bujoli, J.-M. Bouler, Novel biomaterials for bisphosphonate delivery. Biomat . 26 (14) 2073-2080

[36] K.H. Karlsson, M. Rönnlöf, Property-composition relationships for potentially bioactive glasses, Glastech. Ber. Glass. Sci. Technol. 71 (1998)141-145.

[37] M. Brink, T. Turunen, R-P. Happonen, A. Yli-Urpo, Compositional dependence of bioactivity of glasses in the system Na2O-K2O-MgO-CaO-B2O3-P2O5-SiO2, J. Biomed. Mater. Res. 37 (1997) 114-121.

[38] H. Roussière, G. Montavon, S. Laib, P. Janvier, B. Alonso, F. Fayon, M. Petit, D. Massiot, J-M. Bouler, B. Bujoli, Hybrid materials applied to biotechnologies: coating of calcium phosphates for the design of implants active against bone resorption disorders", J. Mater. Chem. 15 (2005) 3869-3875

[39] K. Hammamia, H. El Fekia , O. Marsanb , C. Drouetb, Adsorption of nucleotides on biomimetic apatite:The case of adenosine 5_ monophosphate (AMP), Appl. Surf. Sci. 353 (2015) 165-172.

[40] M. Johnsson, C.F. Richardson, J.D. Sallis, G.H. Nancollas, Adsorption and mineralization effects of citrate and phosphocitrate on hydroxyapatite, Calcif. Tissue. Int. 49 (1991) 134-137.

[41] E. Wersa , H. Oudadessea, B. Lefeuvrea , O. Merdrignac-Conanecb , A. Barroug, Evaluation of the kinetic and relaxation time of gentamicin sulfate released from hybrid biomaterial Bioglass-chitosan scaffolds, Appl. Surf. Sci. 353 (2015) 200-208. 


\section{Figures captions}

Figure 1: X-ray diffraction of 46S6 and risedronates

Figure 2: X-ray diffraction of 46S6-20 RIS after different incubation times (20, 40, 60 and 80 $\min )$ in the $\mathrm{KCl}$ solution,

Ris: risedronate

Figure 3: FTIR Spectra of 46S6 and Risedronate,

Figure 4: FTIR spectra of 46S6-20 RIS after different incubation times (20, 40, 60 and 80 $\min )$ in the $\mathrm{KCl}$ solution,

Ris: risedronate

Figure 5: RAMAN Spectra of 46S6, pure risedronate, 46S6-8RIS and 46S6-20 RIS after incubation in the $\mathrm{KCl}$ solution,

Ris: risedronates

Figure 6: MAS-NMR ${ }^{31} \mathrm{P}$ of 46S6, 46S6-8RIS, 46S6-12 RIS and 46S6-20 RIS after their incubation in the $\mathrm{KCl}$ solution,

Ris: risedronates 
Figure 7: SEM images of 46S6-8 RIS (A), 46S6-12 RIS (B) and 46S6-20 RIS (C) after its incubation in the $\mathrm{KCl}$ solution,

Ris: risedronates

Figure 8: EDS of 46S6-8RIS, 46S6-12RIS and 46S6-20RIS after 40 of incubation in the $\mathrm{KCl}$ solution.

Ris: risedronates

Figure 9: Kinetic release of silicon from 46S6, 46S6-8RIS, 46S6-12RIS and 46S6-20RIS after different incubation times $(20,40,60$ and $80 \mathrm{~min})$ in the $\mathrm{KCl}$ solution, Ris: risedronates

Figure 10: Kinetic release of Risedronates from 46S6, 46S6-8RIS, 46S6-12RIS and 46S620RIS after different incubation times $(20,40,60$ and $80 \mathrm{~min})$ in the $\mathrm{KCl}$ solution, Ris: risedronates

Figure 11: UV-Visible spectrum of risedronate sodium $(0.2 \mathrm{mM})$ in $\mathrm{KCl}$ solution $1 \mathrm{mM}$ at $\mathrm{pH}=7.4$ and at $25^{\circ} \mathrm{C}$,

Ris: risedronates

Figure 12: UV-Visible spectrum of kinetic risedronate release from pure risedronate, 46S68RIS, 46S6-12RIS and 46S6-20RIS after different incubation times (20, 40, 60 and $80 \mathrm{~min})$ in the $\mathrm{KCl}$ solution.

Ris: risedronates

Figure 13: Relaxation time (T) of 46S6-XRIS (X=8, 12 and $20 \mathrm{~min}$ ) after 0, 20, 40, 60 and 80 of incubation in the $\mathrm{KCl}$ solution.

Ris: risedronates 


\section{Table caption}

Table 1: Contribution and chemical shifts of different species in ${ }^{31} \mathrm{P}$ spectra of bioactive pure glass (46S6) and composites 46S6-XRIS (X=8, 12 and 20).

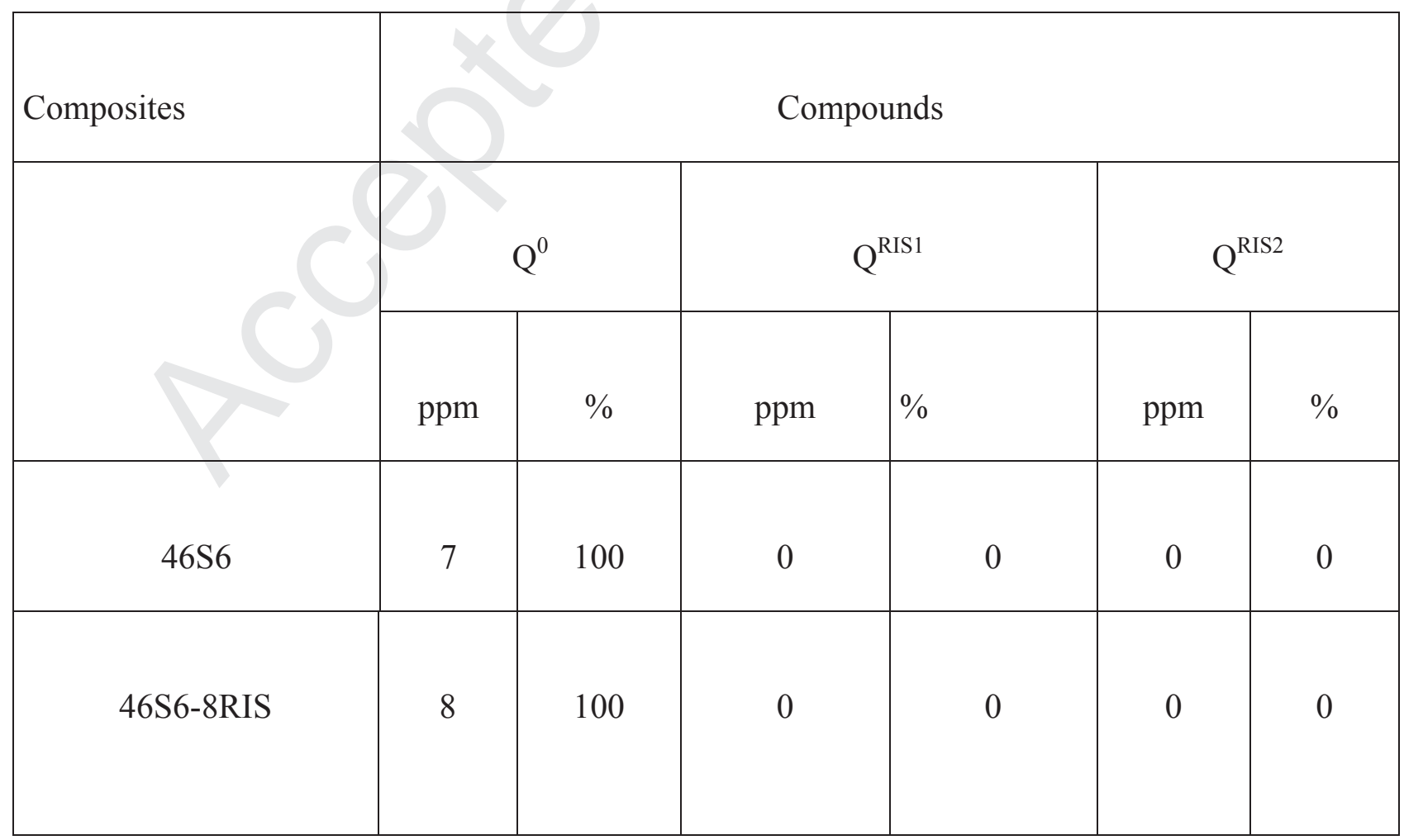




\begin{tabular}{|l|c|c|c|c|c|c|}
\hline 46S6-12RIS & 8 & 93 & 19 & 7 & 0 & 0 \\
\hline 46S6-20RIS & 8 & 88 & 19 & 8 & 15 & 4 \\
\hline
\end{tabular}



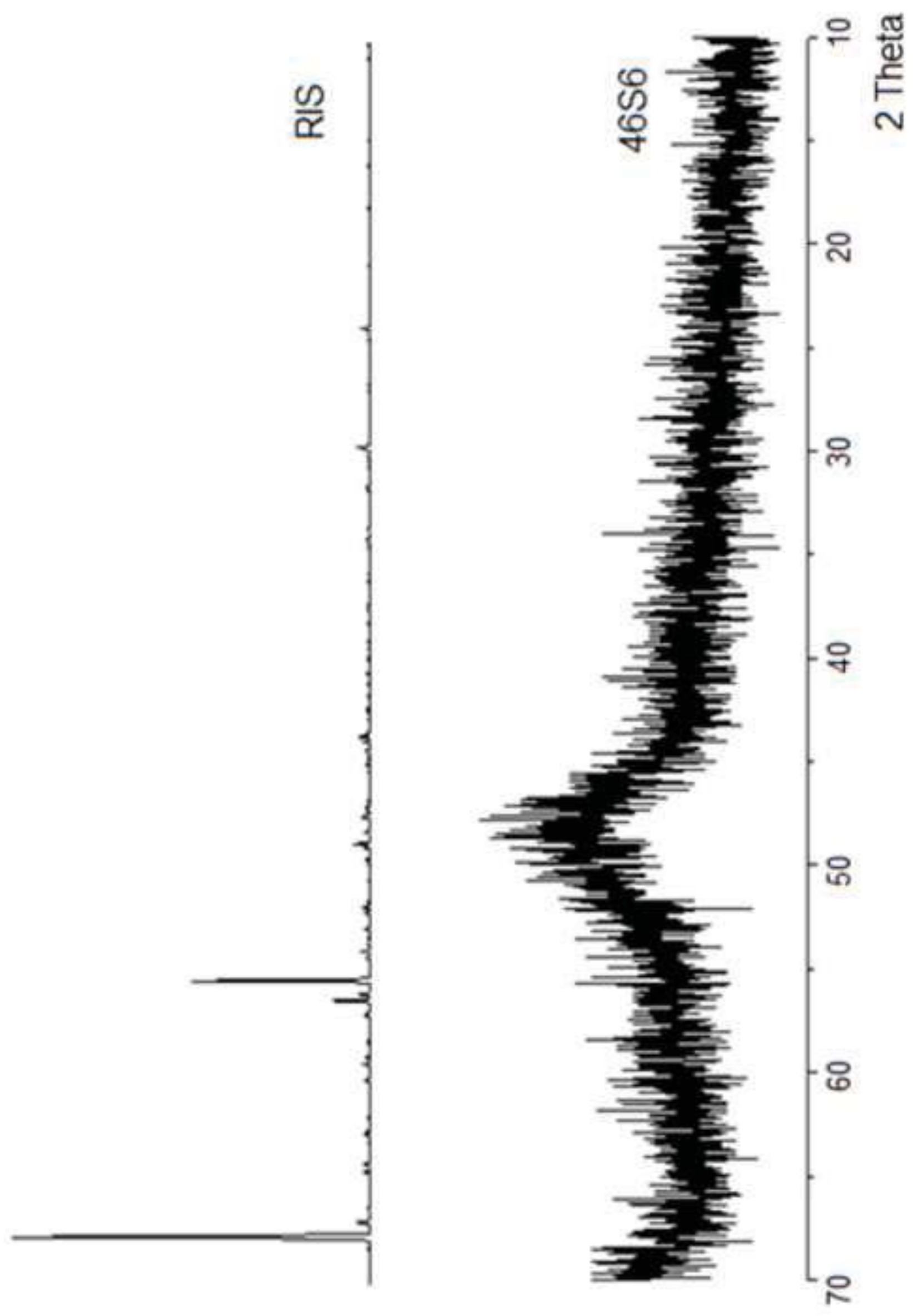

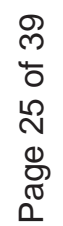



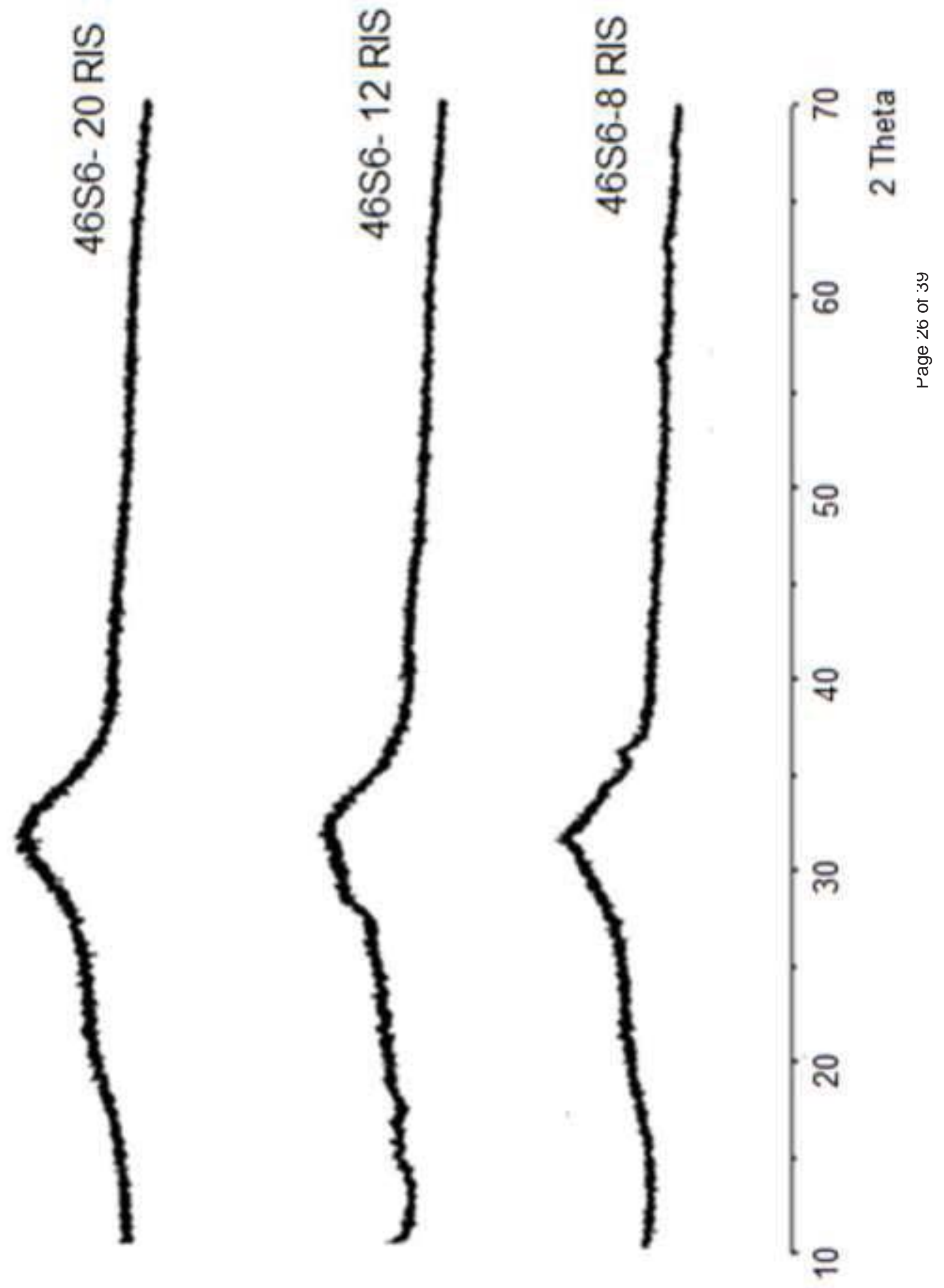

$N$

은 


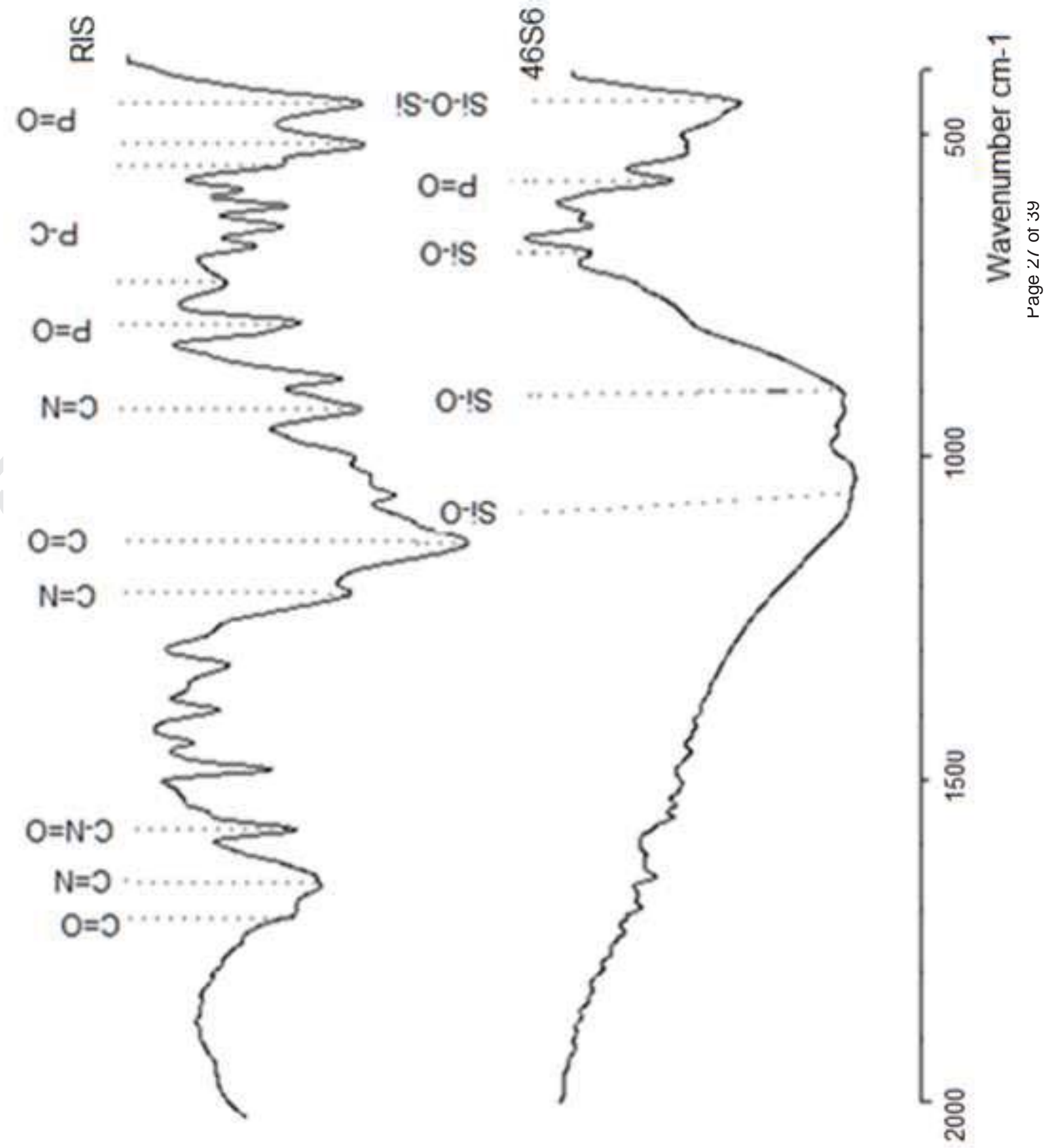




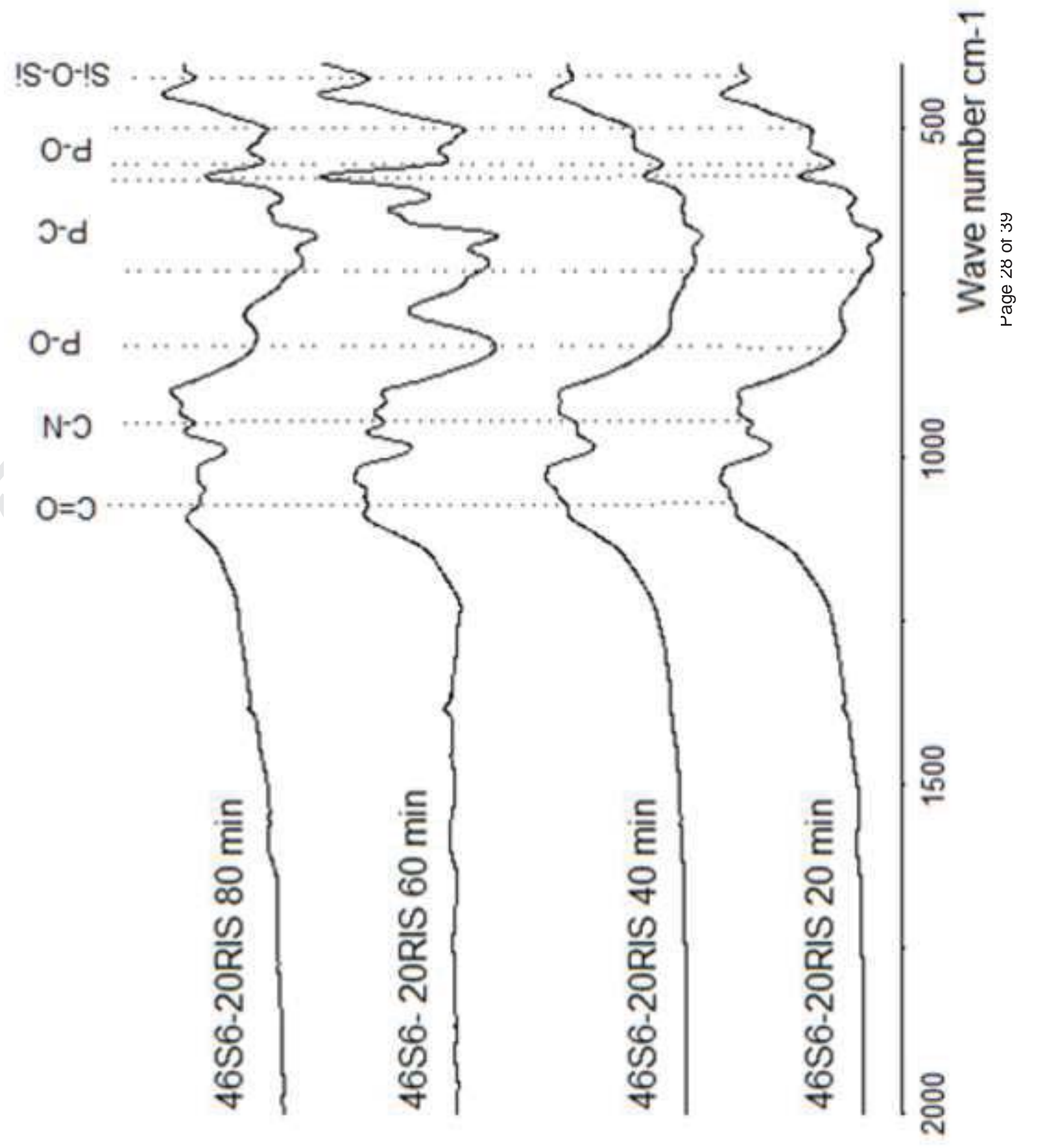




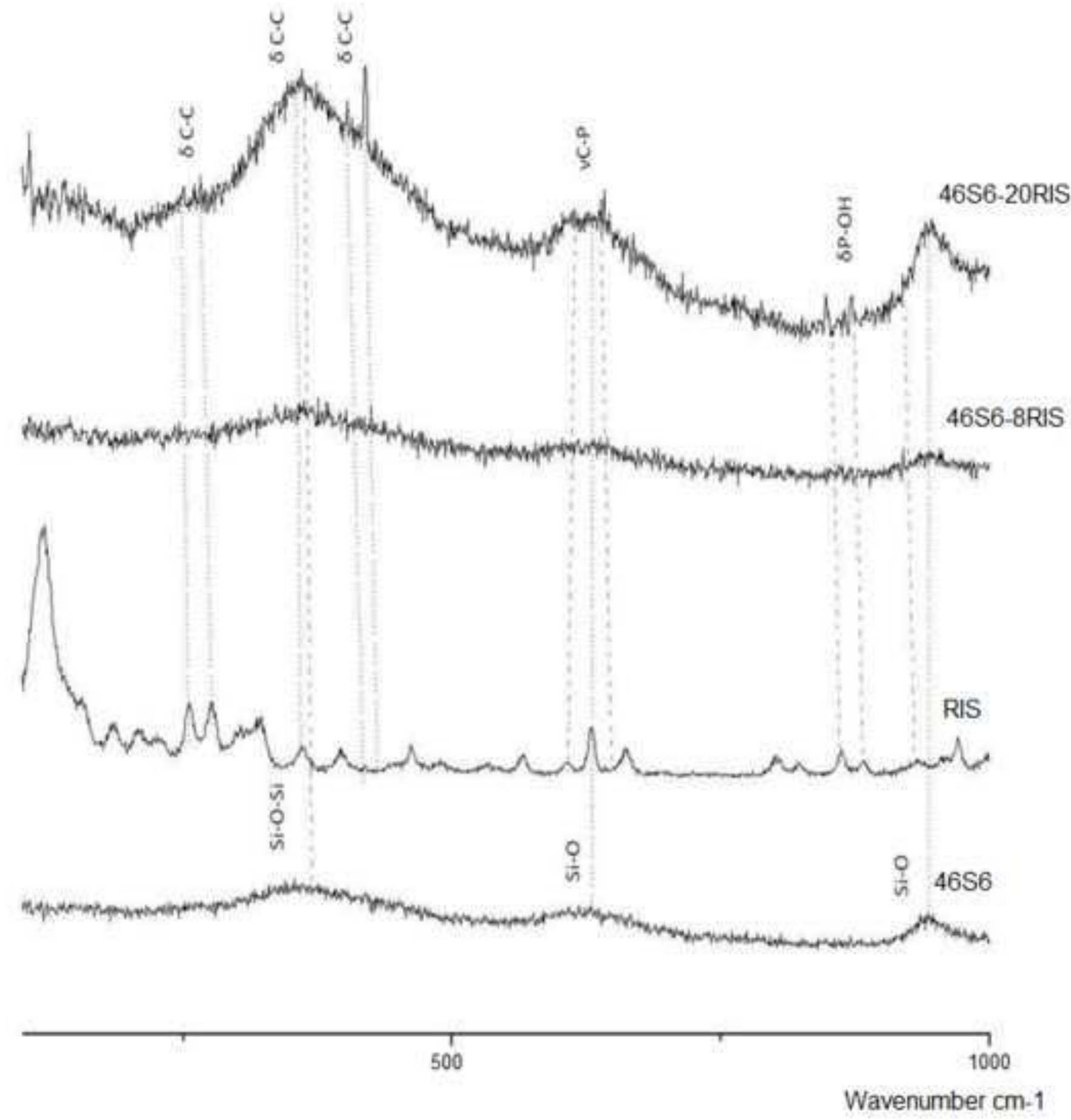




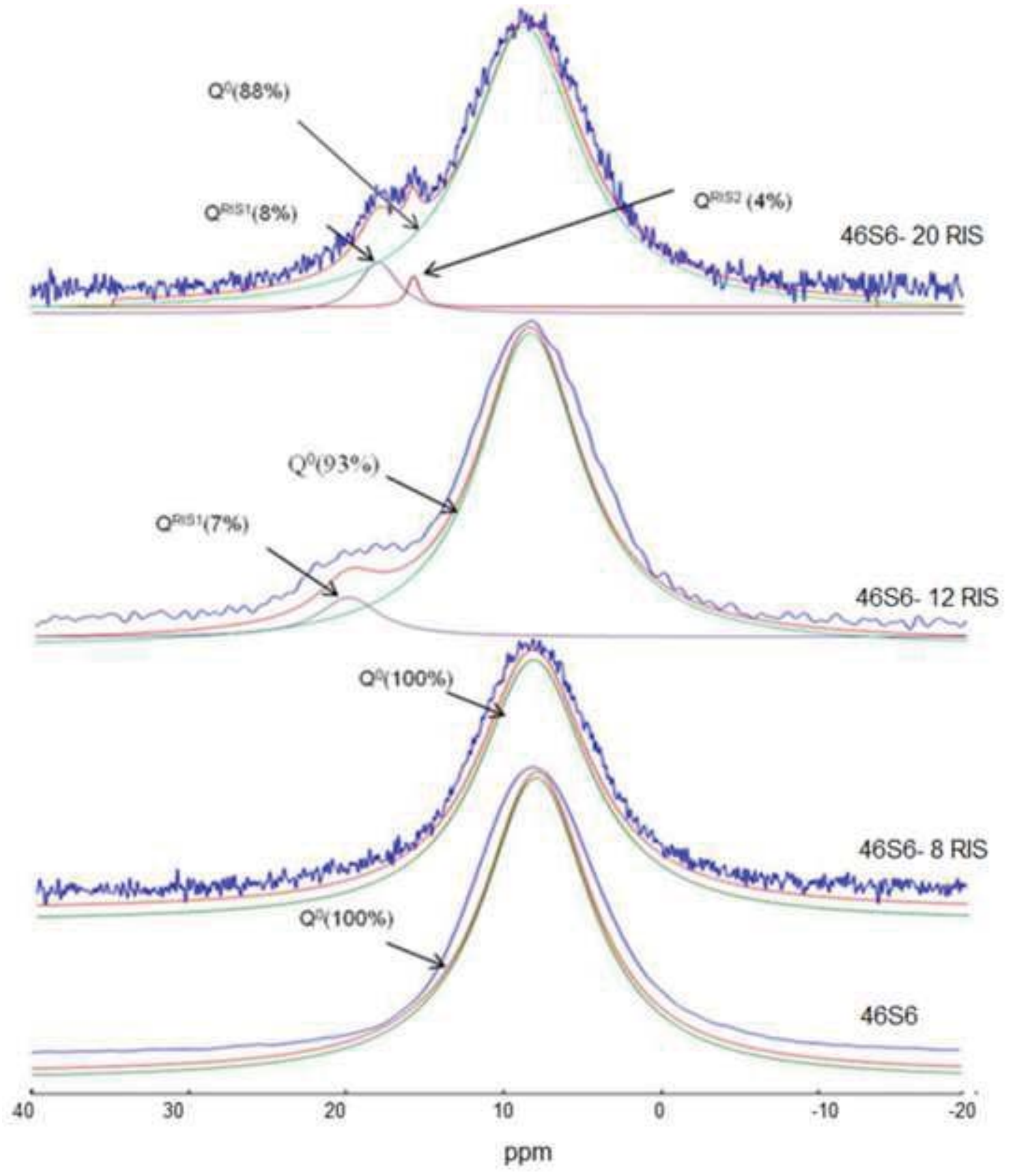




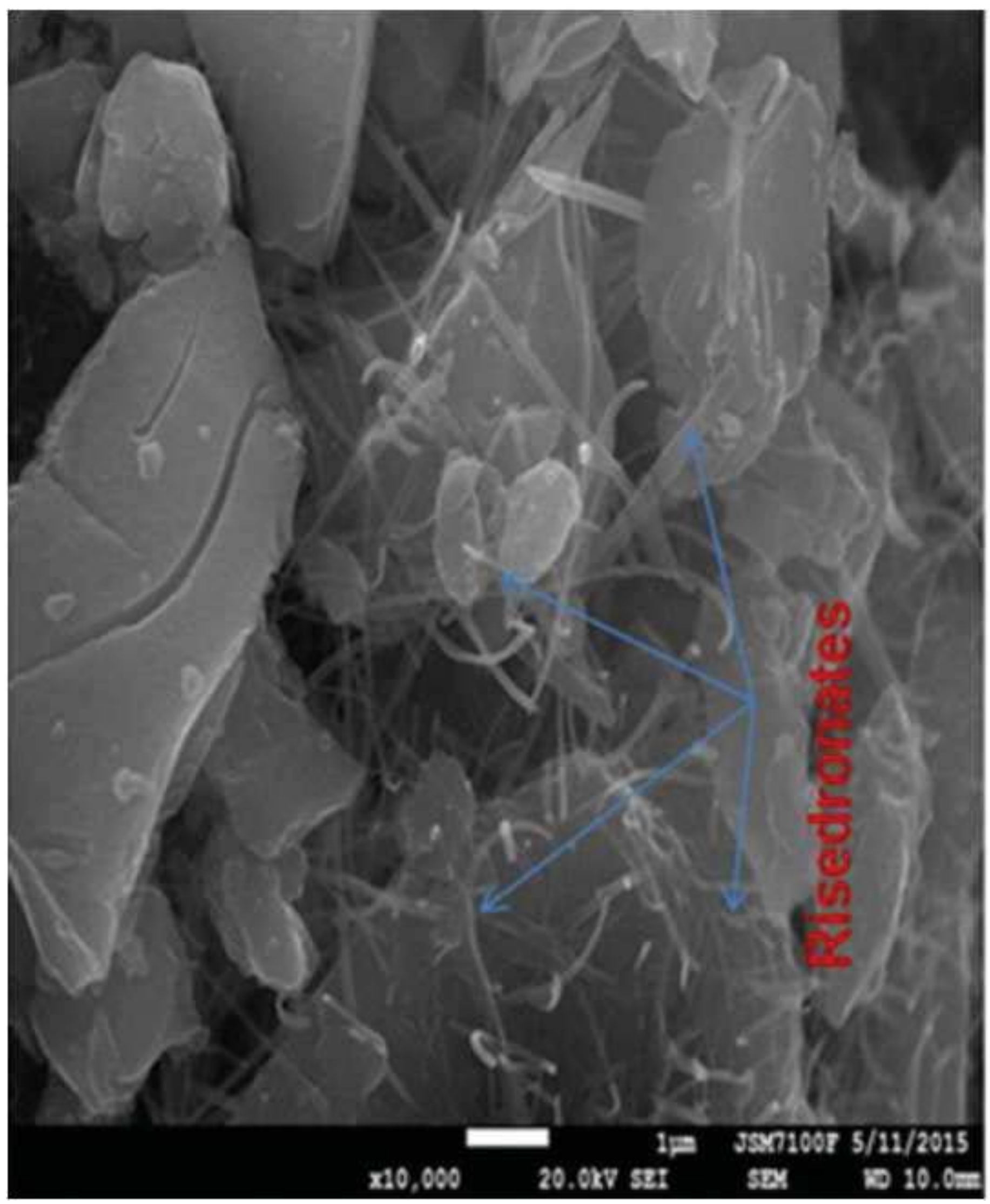




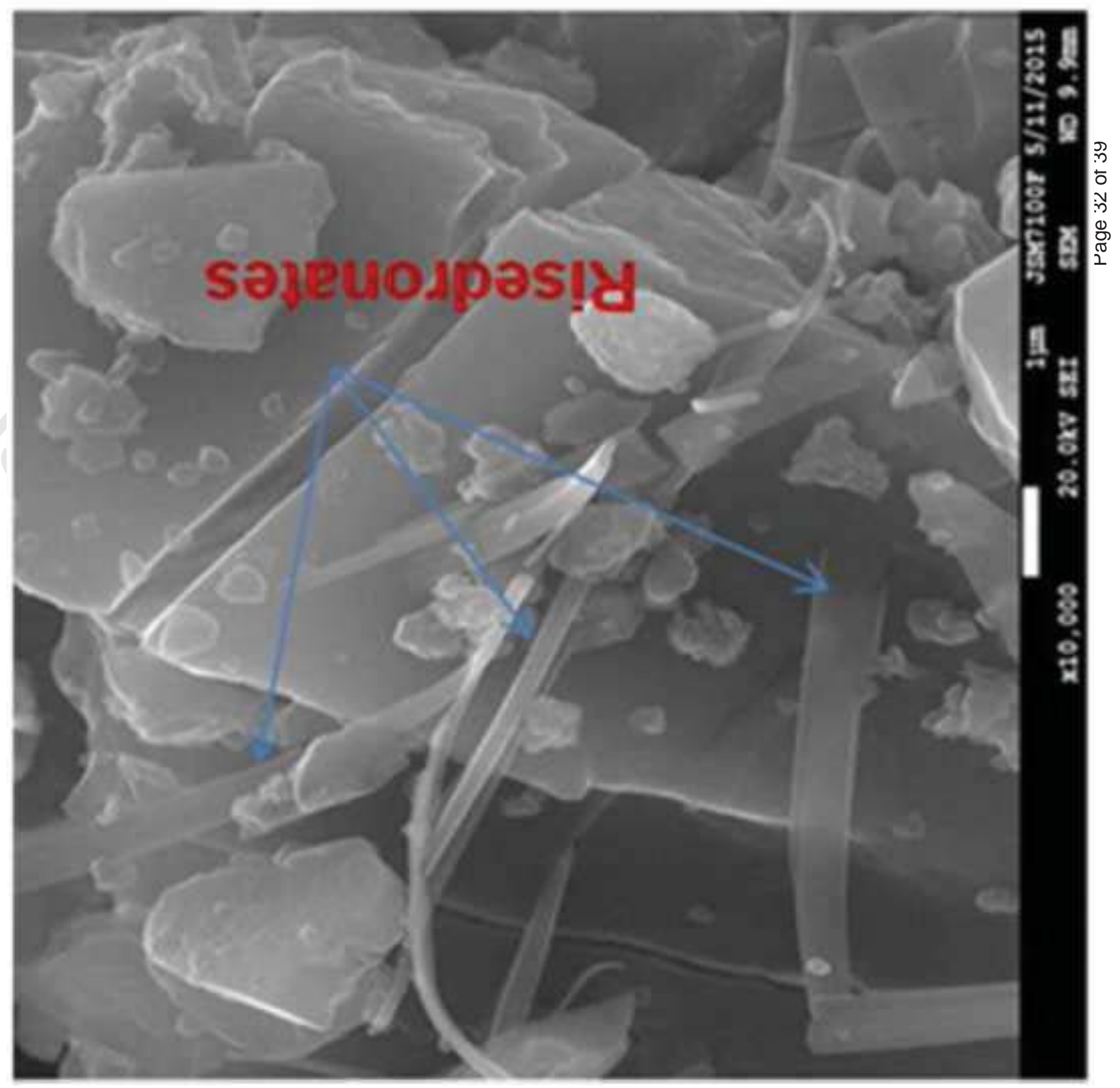

\begin{tabular}{l}
$\stackrel{\infty}{N}$ \\
$\frac{0}{5}$ \\
$\frac{0}{2}$ \\
\hline
\end{tabular} 


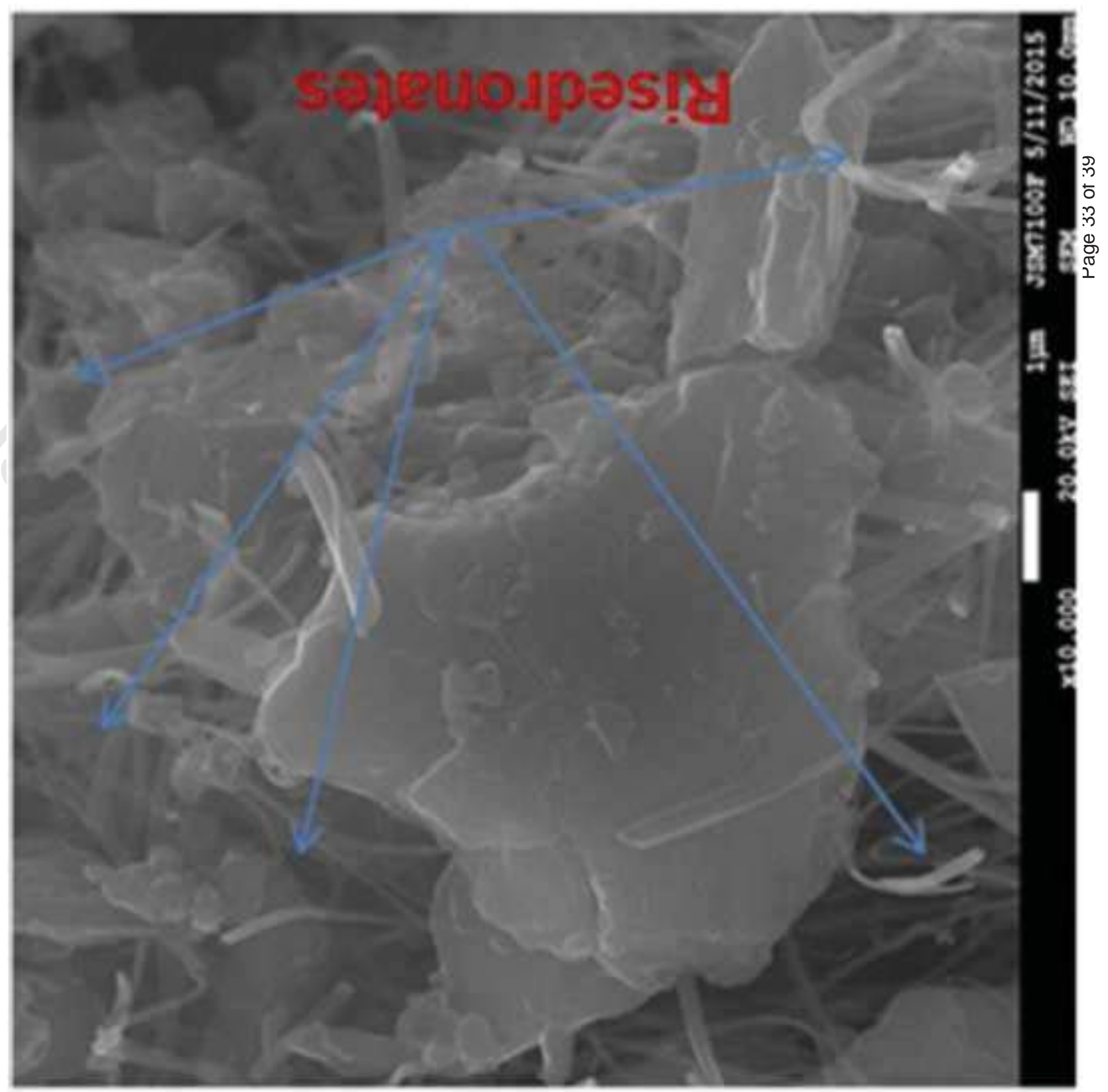

$\mathcal{U}$
$\frac{0}{3}$
$\frac{0}{2}$ 

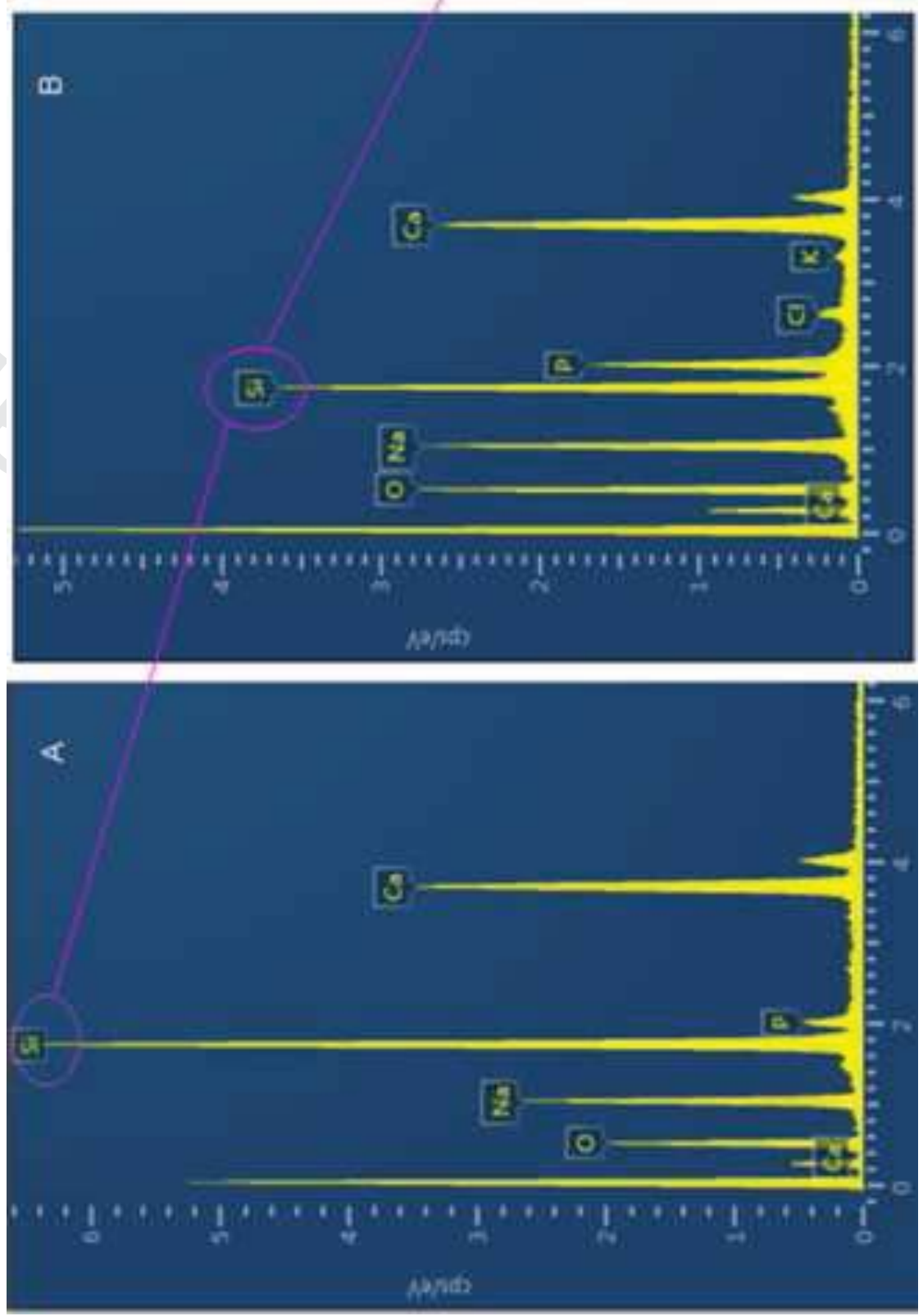


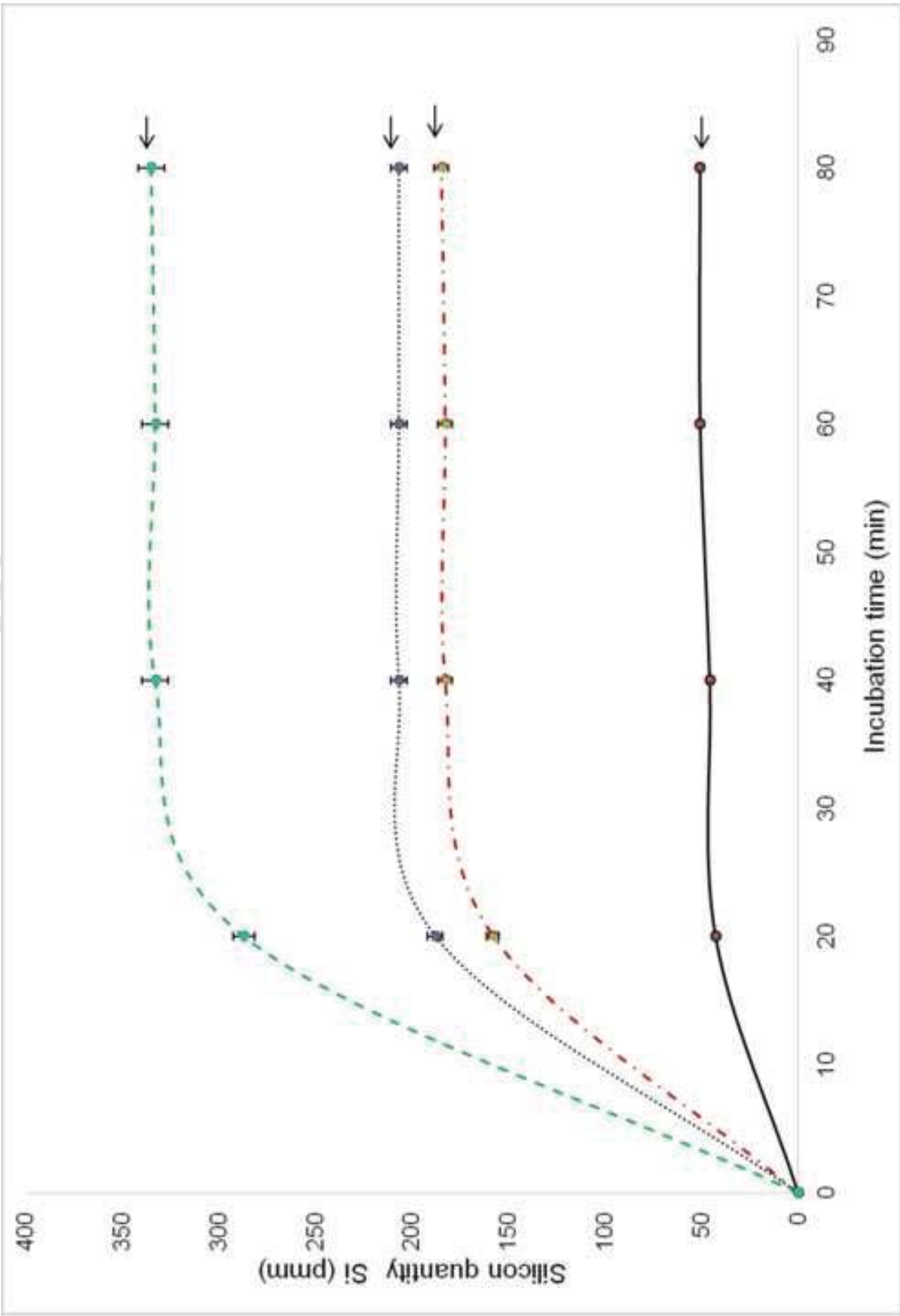

(

은 


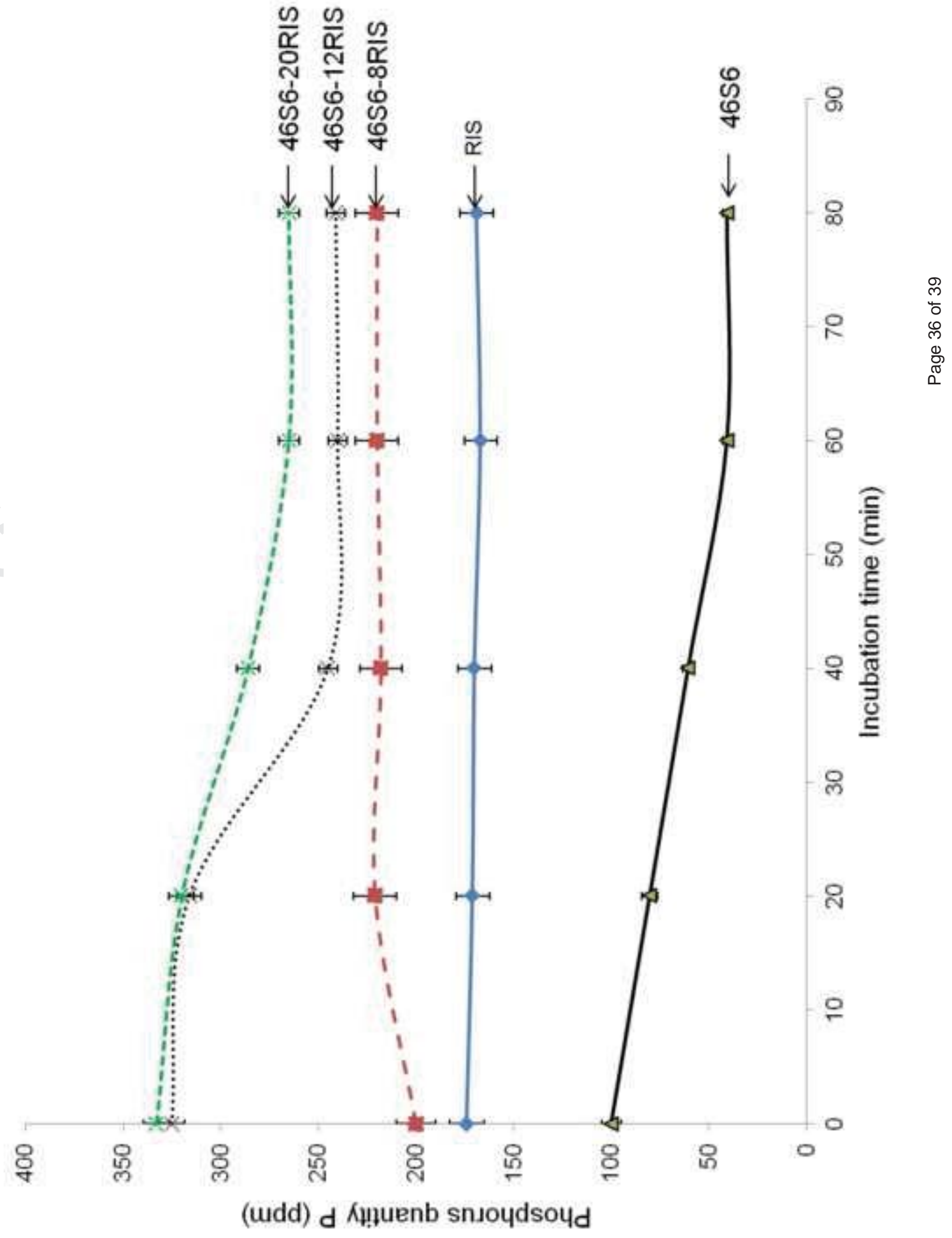




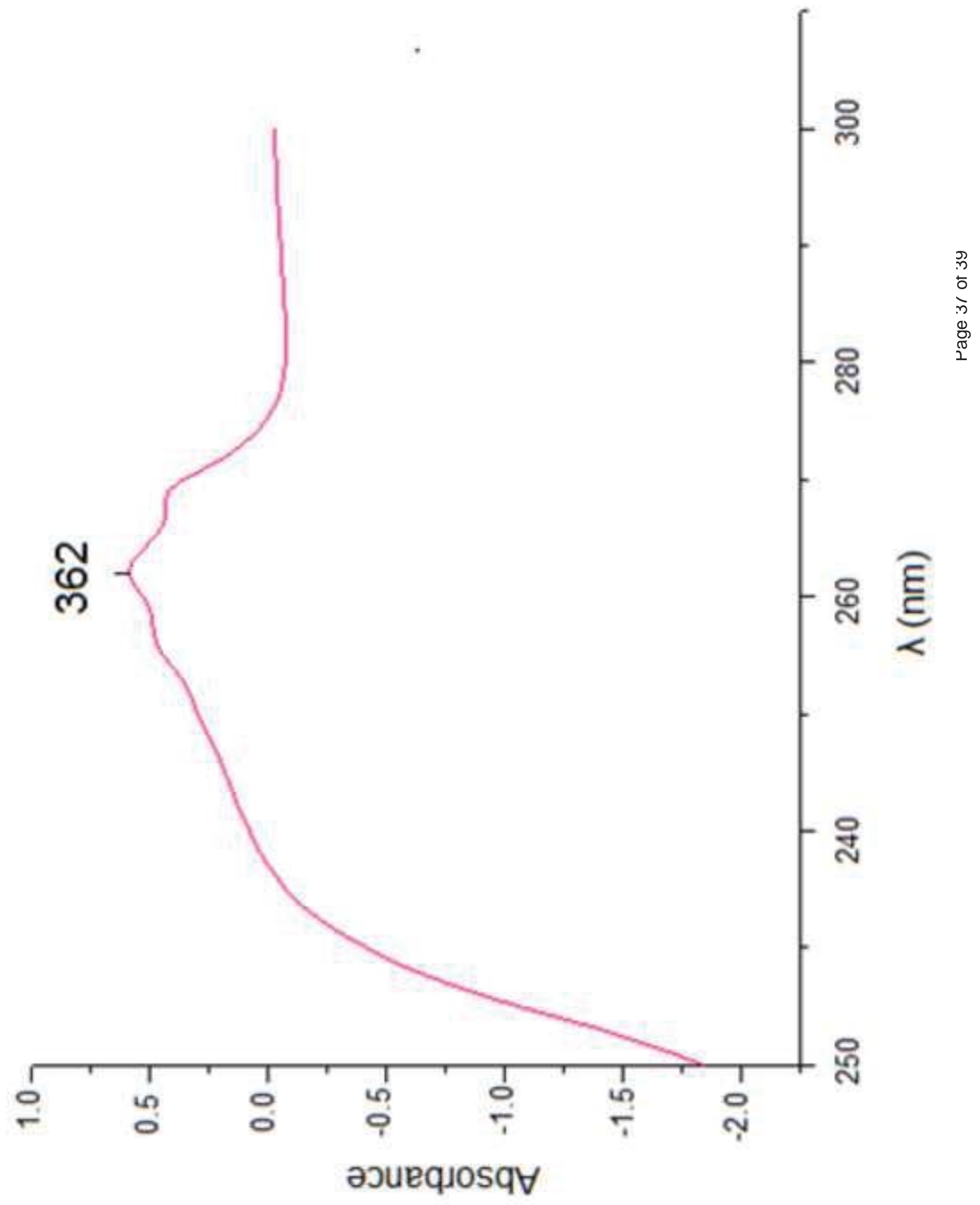

각
일
은 


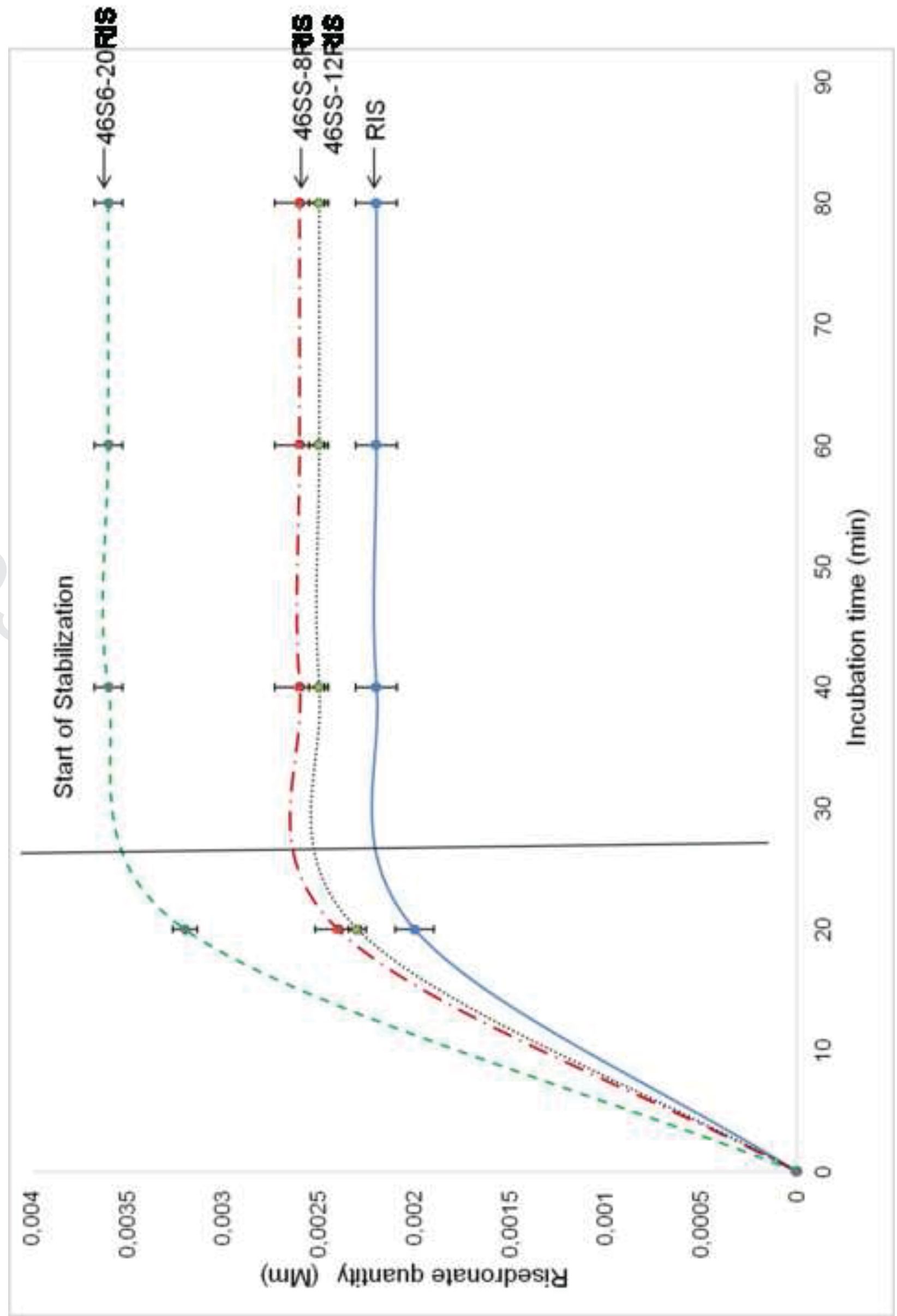




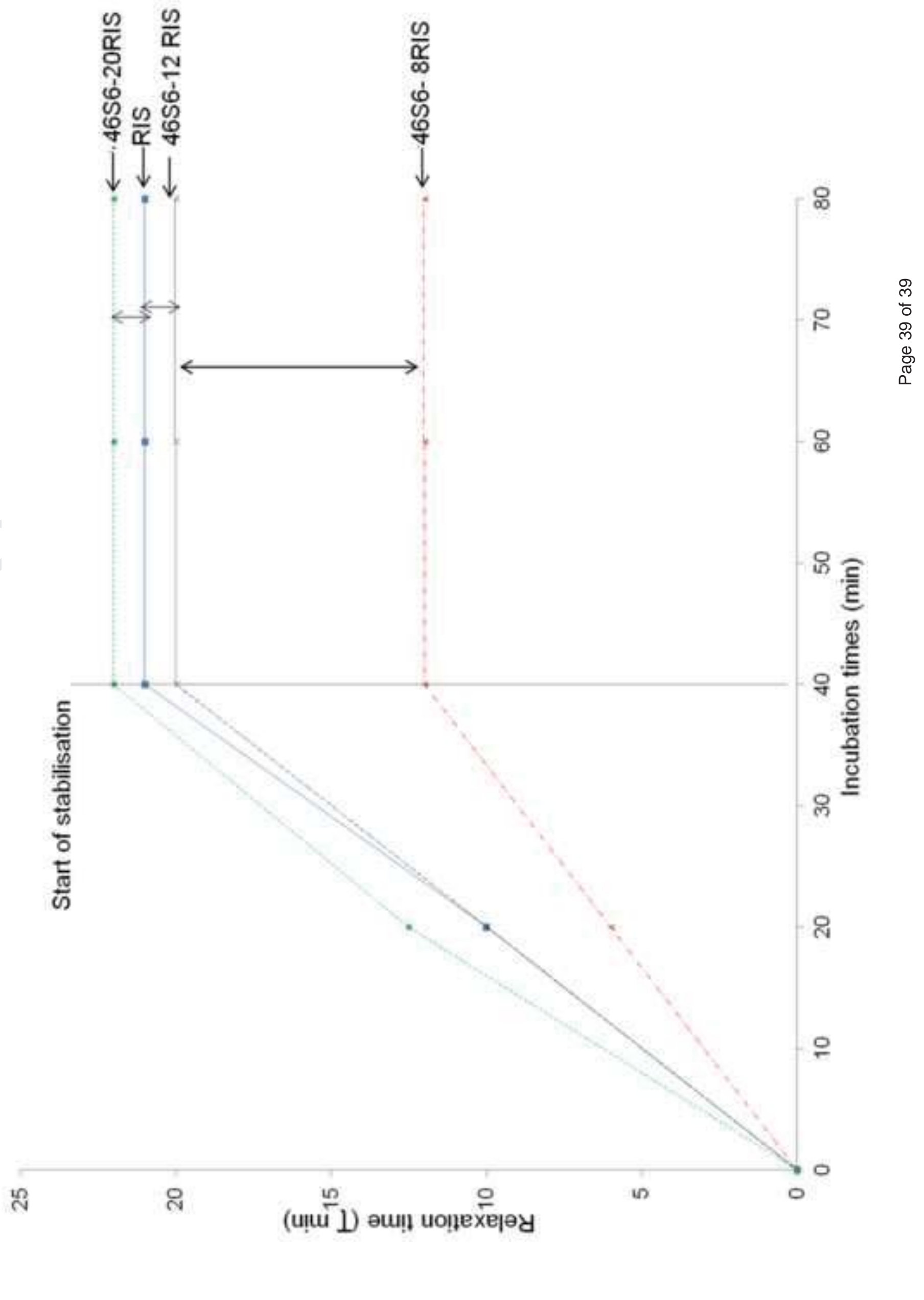

